\title{
Comparação de Parâmetros Estatísticos de Séries de Vazões Censuradas ao Nível Mensal e Diário - Aplicação para Pequenas Centrais Hidrelétricas
}

\author{
Heinz Dieter Fill, Cleverson de Freitas, Eloy Kaviski, Márcia Regina Chella, Miriam Rita Moro Mine \\ Departamento de Hidráulica e Saneamento - Universidade Federal do Paraná \\ heinzfill@yahoo.com
}

Recebido: 11/09/04 - revisado: 27/07/05 - aceito: 15/05/06

\section{RESUMO}

Fill (1989) propôs uma fórmula analítica para avaliar a energia garantida incremental proporcionada por uma pequena central hidrelétrica (PCH) a um sistema elétrico integrado. As variáveis de entrada para essa fórmula são a confiabilidade (tempo de recorrência), o armazenamento do sistema e os parâmetros estatísticos da série de afluências médias anuais, obtidas de vazões diárias censuradas no engolimento máximo da usina. Nagayama (1995) e Bicca (2003) desenvolveram um método para estimar esses parâmetros em locais onde não há dados de vazões. Apesar da maioria das PCH serem a fio de água com regularização apenas diária, tanto a agência reguladora de energia elétrica (ANEEL) como a agência do uso da água (ANA) propõem usar apenas séries de vazões médias mensais censuradas. Neste artigo, investigou-se a influência do uso de vazões censuradas ao nível diário ou médias mensais sobre as estimativas da média e do desvio-padrão das afluências anuais e da energia garantida para onze PCH localizadas nas regiões Sul e Sudeste do Brasil.

O estudo conclui que o uso da censura em vazões médias mensais sistematicamente superestima a capacidade energética de uma PCH.

Palavras-chave: PCH, Energia, Recursos Hidricos.

\section{INTRODUCÃO}

A Resolução nº 394, de 04 de dezembro de 1998, da Agência Nacional de Energia Elétrica - ANEEL (Aneel, 1998-a), estabelece os critérios para enquadramento, no Brasil, de empreendimentos na condição de pequenas centrais hidrelétricas, geralmente designadas por PCH. Entre estes critérios, os mais importantes são: as limitações de potência e área do reservatório. De acordo com a Resolução no 395 da ANEEL, de 04 de dezembro de 1998 (Aneel, 1998-b), os empreendimentos com potência superior a 1.000 $\mathrm{kW}$ e igual ou inferior a $30.000 \mathrm{~kW}$, com área total de reservatório igual ou inferior a $3,0 \mathrm{~km}^{2}$, são considerados como aproveitamentos $\mathrm{PCH}$ e terão suas autorizações para exploração outorgadas após a aprovação dos respectivos projetos básicos pela ANEEL. A área citada do reservatório será delimitada pela cota do nível de água associada à vazão de cheia com tempo de recorrência de 100 anos.

Dessa forma as Centrais Hidrelétricas ficam classificadas, segundo a potência, em três grandes grupos (Eletrobrás, 2002):
- $\quad$ Mini Centrais Hidrelétricas - MCH com $\mathrm{P} \delta$ 1 MW

- Pequenas Centrais Hidrelétricas - PCH com $1 \mathrm{MW}<\mathrm{P} \delta 30 \mathrm{MW}$

- Grandes Centrais Hidrelétricas ou Usinas Hidrelétricas - UHE com P > 30 MW.

Além de definir o enquadramento de um aproveitamento hidrelétrico nesses grupos, a ANEEL procurou definir métodos simplificados para a avaliação energética de $\mathrm{PCH}$ e $\mathrm{MCH}$, dado que nesses locais a disponibilidade e confiabilidade de dados hidrológicos são geralmente muito menores do que nos locais de UHE. Por outro lado, as PCH tendem ter uma crescente importância na matriz energética nacional, não só pelo expressivo número de unidades, mas também por seu importante papel no desenvolvimento social e econômico (Badanhan e Mariontoni, 1997), o que justifica o interesse em se desenvolver métodos próprios para avaliar a sua contribuição energética, levando em conta as suas particularidades. 
Um parâmetro importante na avaliação energética de uma usina hidrelétrica é o montante de energia que a usina pode suprir ao sistema elétrico interligado com dado nível de confiabilidade. Esse valor é denominado energia garantida. Têm sido propostas duas formas para avaliar a energia garantida: (1) pelo valor incremental do mercado, que pode ser atendido pela adição da usina, mantendose constante o nível de confiabilidade (Canambra, 1969; Fill, 1989), e (2) pela média ponderada da geração da usina dentro do sistema, atendendo um mercado com um dado nível de confiabilidade, sendo os pesos iguais ao custo marginal do sistema a cada instante (Fortunato, et al., 1990).

Para efeitos comerciais, a ANEEL define para cada usina a chamada "energia assegurada", através de certificados, cuja função é limitar os contratos de suprimento e balizar a expansão do sistema elétrico (Clemente e Ramos, 2003).

Com o objetivo de incentivar a construção de novas usinas, e ao mesmo tempo evitar contratos especulativos que poderiam diminuir a confiabilidade de atendimento, a nova regulamentação exige que a energia $(M W h)$ e a potência (MW) contratadas por um agente gerador, tenham o respaldo de uma geração física capaz de assegurar os respectivos suprimentos. No caso de geração hidrelétrica, este respaldo corresponde à energia assegurada da usina, que teoricamente deve igualar à energia garantida com um risco aceitável para a sociedade.

Tendo em vista que a quase totalidade das PCH é constituída por usinas a fio de água, sem regularização a montante, e sendo o seu efeito sobre a geração das outras usinas do sistema desprezível, a avaliação da energia garantida resume-se, inicialmente, ao cálculo da média das energias afluentes, censuradas pelo engolimento máximo das turbinas, de uma série de afluências sobre um período adequado. Esse período corresponde a uma seqüência de vazões afluentes cuja probabilidade de ocorrência traduza um risco de falha aceitável para a sociedade. Em seguida, basta multiplicar essa média pela produtividade da usina e descontar as indisponibilidades da usina através de coeficientes apropriados (TEIF e TEIP) para se obter a energia assegurada. Resulta:

$\mathrm{E}_{\mathrm{a}}=8,76 \cdot \mathrm{K} \cdot \overline{\mathrm{Q}} \cdot(1-\mathrm{TEIF}) \cdot(1-\mathrm{TEIP})[\mathrm{MWh} / \mathrm{ano}]$

sendo:

TEIF - taxa efetiva de indisponibilidade forçada;
TEIP - taxa efetiva de indisponibilidade programada;

$\overline{\mathrm{Q}}$ - vazão média censurada $\left(\mathrm{m}^{3} / \mathrm{s}\right)$, dada por:

$$
\overline{\mathrm{Q}}=\frac{1}{\mathrm{~T}} \sum_{\mathrm{t} \in \mathrm{T}} \min \left(\mathrm{Q}_{\mathrm{t}} ; \mathrm{Q}^{*}\right)
$$

onde:

$\mathrm{Q}_{\mathrm{t}}$ - vazão afluente no tempo t;

$\mathrm{Q}^{*}$ - vazão máxima de engolimento da usina;

$\mathrm{T}$ - período considerado;

$\mathrm{K}$ - produtividade média da usina $\left(\mathrm{kW} / \mathrm{m}^{3} . \mathrm{s}\right)$, dada por:

$$
\mathrm{K}=\frac{\rho \cdot \mathrm{g} \cdot \mathrm{H}_{\mathrm{L}} \cdot \eta}{1000}=\mathrm{g} \cdot \mathrm{H}_{\mathrm{L}} \cdot \eta
$$

sendo:

$\mathrm{g}$ - aceleração da gravidade $\left(9,81 \mathrm{~m} / \mathrm{s}^{2}\right)$;

$\mathrm{H}_{\mathrm{L}}$ - queda líquida (m)

$\eta$ - rendimento global da central (p.u);

$\rho$ - densidade da água $\left(1000 \mathrm{~kg} / \mathrm{m}^{3}\right)$.

No caso de se optar pela série histórica de afluências, há divergências entre os agentes do sistema elétrico brasileiro com relação ao período a ser usado para o cálculo dessa média. A Agência Nacional de Águas - ANA - advoga o uso do período crítico histórico (CGSE, 2002) e a ANEEL propõe um período histórico qualquer com duração mínima de 30 anos (Brasil, 2002). A análise dessa divergência está fora do escopo deste trabalho que se concentra na análise dos efeitos da censura das afluências, considerando diferentes discretizações nas séries de vazões sobre os resultados da avaliação energética de uma PCH. Uma comparação das propostas da ANA e da ANEEL foi apresentada recentemente em outro artigo (Fill et al., 2003).

\section{METODOLOGIA}

Fill (1979) classifica as características das fontes de geração hidráulicas em três categorias: características naturais (séries de vazões), características físicas de projeto (potência instalada) e carac 
Tabela 1 - Locais Analisados no Estudo

\begin{tabular}{|c|c|c|c|c|c|c|c|c|c|}
\hline PCH & Rio & $\begin{array}{c}\text { Estação } \\
\text { Fluviométrica } \\
\text { drenagem da } \\
\text { estação }(\mathrm{km} 2)\end{array}$ & $\begin{array}{c}\text { Área de } \\
(\mathrm{MW})\end{array}$ & $\begin{array}{c}\text { Potência } \\
\text { bruta } \\
(\mathrm{m})\end{array}$ & $\begin{array}{c}\text { Área de } \\
\text { drenagem da } \\
\text { usina }(\mathrm{km} 2)\end{array}$ & $\begin{array}{c}\text { Q } \\
\text { média } \\
\left(\mathrm{m}^{3} / \mathrm{s}\right)\end{array}$ & $\begin{array}{c}\text { Q } \\
\text { máxima } \\
\left(\mathrm{m}^{3} / \mathrm{s}\right)\end{array}$ & $\begin{array}{c}\text { Desvio } \\
\text { Padrão } \\
\left(\mathrm{m}^{3} / \mathrm{s}\right)\end{array}$ \\
\hline Cajuru & Pará & 40150000 & 2507 & 7,20 & 20,50 & 2230 & 38,14 & 43,48 & 18,52 \\
Santana do Jacaré & Jacaré & 61202000 & 1547 & 3,50 & 25,00 & 1469 & 29,34 & 18,78 & 12,62 \\
Inferno & das Mortes & 61135000 & 5586 & 30,00 & 43,00 & 6100 & 112,69 & 86,77 & 52,50 \\
\hline Cachoeira da Fumaça & Ingaí & 61075000 & 1008 & 3,20 & 14,00 & 1010 & 19,30 & 28,37 & 10,17 \\
Salto Grande & Atibaia & 62676000 & 1920 & 4,55 & 10,00 & 2062 & 27,28 & 56,47 & 6,51 \\
Salto Caiacanga & Iguaçu & 65035000 & 3662 & 9,5 & 13,7 & 3450 & 67,67 & 85,94 & 17,39 \\
PCH 01 & da Várzea & 65135000 & 602 & 3,0 & 14,6 & 585 & 11,59 & 25,61 & 1,58 \\
PCH 02 & Marombas & 71498000 & 3800 & 20,0 & 23,7 & 3800 & 82,32 & 104,55 & 32,57 \\
PCH 03 & Turvo & 81125000 & 392 & 8,0 & 87,9 & 392 & 7,51 & 11,34 & 1,49 \\
PCH 04 & Itajaí do Sul & 83250000 & 1774 & 10,0 & 29,7 & 1774 & 32,73 & 41,89 & 27,9 \\
PCH 05 & Tijucas & 84071000 & 1042 & 15,0 & 45,1 & 1042 & 22,89 & 41,43 & 3,22 \\
\hline
\end{tabular}

terísticas operacionais (limites de depleção). Entre as características físicas, a potência instalada e a queda líquida de referência são dois parâmetros de extrema importância na viabilidade de uma PCH, assim como em qualquer aproveitamento hidrelétrico. Ambas influem decisivamente nos custos de implementação e na energia gerada e, portanto, no retorno econômico do empreendimento. A definição da queda líquida, além de determinar a produtividade, ainda pode influenciar decisivamente a área inundada, o que além de afetar os custos, tem grande importância nos impactos ambientais do projeto.

O impacto da potência instalada se manifesta de duas formas: (1) diretamente pela possibilidade do atendimento de demandas máximas (MW) remunerado por tarifa específica e (2) indiretamente pelo aumento da geração de energia (MWh) provocado pelo aumento do nível de censura às vazões afluentes. É este último efeito que é analisado no presente artigo, usando-se a técnica de simulação sobre o registro histórico de vazões, no período de 1946 a 1996.

$\mathrm{O}$ efeito da censura sobre a energia assegurada, manifesta-se de duas formas: (1) pelo nível de censura, afetando diretamente a média e outras estatísticas amostrais por reduzir o valor das vazões turbinadas em vários subperíodos e, (2) pela escolha do intervalo de discretização das vazões (diário, semanal, mensal) sobre o qual incide a censura. Por exemplo, no caso de vazões médias mensais, há ca- sos em que, apesar da média mensal ser inferior ao nível de censura, em alguns dias a vazão supera esse nível, fazendo com que a censura ao nível mensal tenda a superestimar a disponibilidade energética da usina.

No presente trabalho este efeito é avaliado em 11 locais de $\mathrm{PCH}$, situados nas regiões $\mathrm{Sul} \mathrm{e} \mathrm{Su}-$ deste do Brasil, variando-se o nível de censura e efetuando a censura sobre vazões médias mensais e diárias. Os locais analisados estão listados na tabela 1 , juntamente com suas características de projeto e os parâmetros estatísticos média e desvio padrão, além da vazão de engolimento máximo da PCH. Também é indicada a estação fluviométrica utilizada para estimar a série de vazões afluentes no local.

Os cálculos para obtenção da vazão média censurada foram efetuados conforme a expressão (4):

$$
\overline{\mathrm{Q}}_{\mathrm{c}}=\Sigma \mathrm{X}_{\mathrm{t}} / \mathrm{n}
$$

onde:

$$
X_{t}=\min \left(Q_{t}, Q^{*}\right)
$$

$Q_{t}$ - vazão do mês ou dia t;

$\mathrm{Q}^{*}$ - nível de censura (vazão de engolimento máximo); 
n - número de meses ou dias do período histórico adotado (1946 a 1996).

Para estimar as vazões afluentes de cada PCH analisada, foi utilizada a estação fluviométrica mais próxima, sendo as vazões transferidas mediante a relação entre áreas de drenagem.

$$
\mathrm{Q}_{\text {pch }}=\left(\mathrm{A}_{\text {pch }} / \mathrm{A}_{\text {posto }}\right) \mathrm{x}_{\text {posto }}
$$

sendo:

$\mathrm{Q}_{\mathrm{pch}}$ - vazão afluente da usina PCH analisada;

$\mathrm{Q}_{\text {posto }}$ - vazão afluente da estação fluviométrica mais próxima à usina $\mathrm{PCH}$ analisada;

$\mathrm{A}_{\mathrm{pch}}$ - área de drenagem da usina $\mathrm{PCH}$ analisada;

$\mathrm{A}_{\text {posto }}$ - área de drenagem da estação fluviométrica mais próxima à usina $\mathrm{PCH}$ analisada.

Esse procedimento foi usado tanto para médias mensais como também para vazões médias diárias, válido neste caso dada à proximidade entre posto $\mathrm{e}$ $\mathrm{PCH}$.

Além da análise da vazão média foi analisado o comportamento do desvio padrão das afluências censuradas em função do nível de censura e do intervalo de discretização. Neste caso:

$$
\mathrm{S}_{\mathrm{c}}=\sqrt{\Sigma\left(\mathrm{X}_{\mathrm{t}}-\overline{\mathrm{Q}}_{\mathrm{c}}\right)^{2} /(\mathrm{n}-1)}
$$

onde os símbolos têm o mesmo significado que na equação (4).

Fill (1989) propôs uma fórmula analítica para avaliar a contribuição incremental da energia garantida proporcionada por uma $\mathrm{PCH}$, para um dado nível de confiabilidade, em função de parâmetros estatísticos das afluências censuradas. Nagayama (1995) e Bicca (2003) propuseram uma metodologia para avaliar as estatísticas da distribuição de probabilidades das afluências médias anuais censuradas ao nível diário, necessárias para a aplicação da fórmula de Fill. As estatísticas mais relevantes são a média e o desvio padrão das afluências médias anuais quando censuradas ao nível diário ou mensal. A média é dada pela equação (2) e o desvio padrão é dado por:

$$
S^{*}=\sqrt{\Sigma\left(\bar{Q}_{j}-\bar{Q}_{c}\right)^{2} /(m-1)}
$$

sendo:
$\overline{\mathrm{Q}}_{j}$ - vazão média das vazões censuradas do ano $\mathrm{j}$;

$\overline{\mathrm{Q}}_{\mathrm{c}}$ - média de longo período das vazões censuradas;

$\mathrm{m}$ - o número de anos do período (50 anos).

\section{RESULTADOS}

Os resultados são apresentados nas figuras 1 a 6 , sempre na forma adimensional, sendo:

q - vazão média de longo período;

$\mathrm{q}^{*}$ - limite da censura;

$\overline{\mathrm{q}}_{\mathrm{d}, \mathrm{c}}$ - vazão média de longo período censurada a nível diário;

$\overline{\mathrm{q}}_{\mathrm{m}, \mathrm{c}}-$ vazão média censurada;

S - desvio padrão;

$\mathrm{S}_{\mathrm{d}, \mathrm{c}}$ - desvio padrão das vazões médias diárias censuradas;

$\mathrm{S}_{\mathrm{a}, \mathrm{c}}$ - desvio padrão das vazões médias anuais censuradas;

$\mathrm{S}_{\mathrm{m}, \mathrm{c}}$ - desvio padrão das vazões médias censuradas.

O nível de censura foi modulado pela vazão média de longo termo não censurada e, nas figuras 1 a 3, os parâmetros estatísticos (média e desvio padrão) foram modulados pelos seus valores naturais nas séries não censuradas. Nas figuras 4 a 6 , o eixo das ordenadas corresponde à razão das estatísticas censuradas ao nível mensal e diário, respectivamente. A faixa das vazões de engolimento previstas nas onze PCH analisadas, também, é destacada nas figuras.

A figura 1 ilustra a variação da média de longo termo com o nível de censura diário para os diversos locais de PCH analisados, notando-se a pequena dispersão das curvas.

Como era esperado, as curvas tendem a zero e a um nos extremos, tomando o gráfico a forma de uma reta a $45^{-}$para níveis de censura abaixo da vazão mínima. Para os níveis de potência instalada usuais em PCH (0,6 a 2 vezes a vazão média), a média censurada varia aproximadamente de $50 \%$ a $90 \%$ do seu valor não censurado, mostrando que em termos de geração média a motorização de uma PCH integrada deve corresponder pelo menos duas vezes o valor correspondente à vazão média. Isso contraria de certa forma as diretrizes da ANEEL para estudos de inventário e viabilidade de $\mathrm{PCH}$ (Clemente e Ramos, 2002) que sugere uma média 



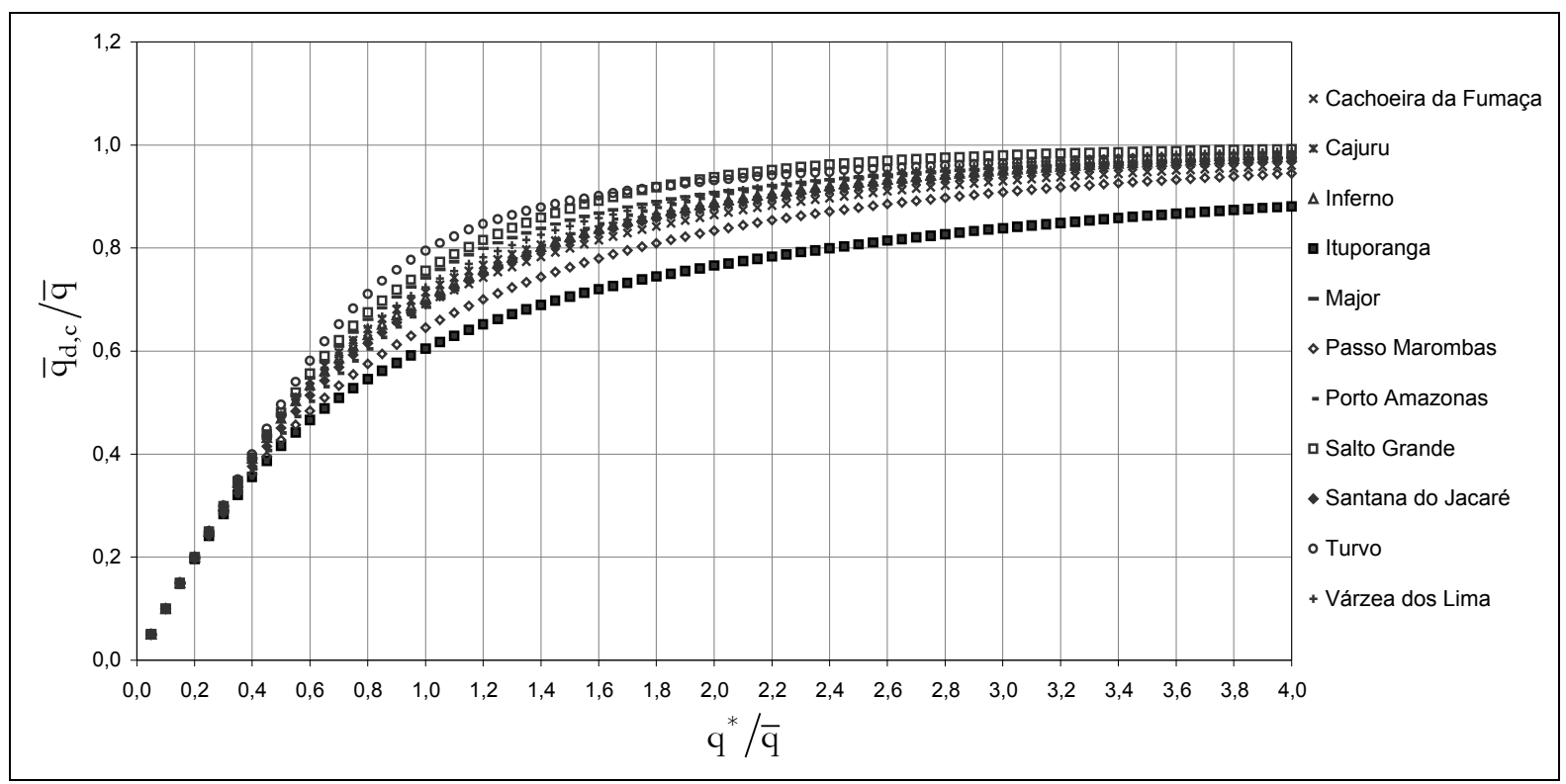

Figura 1 - Influência do nível de censura diário na média de longo termo.

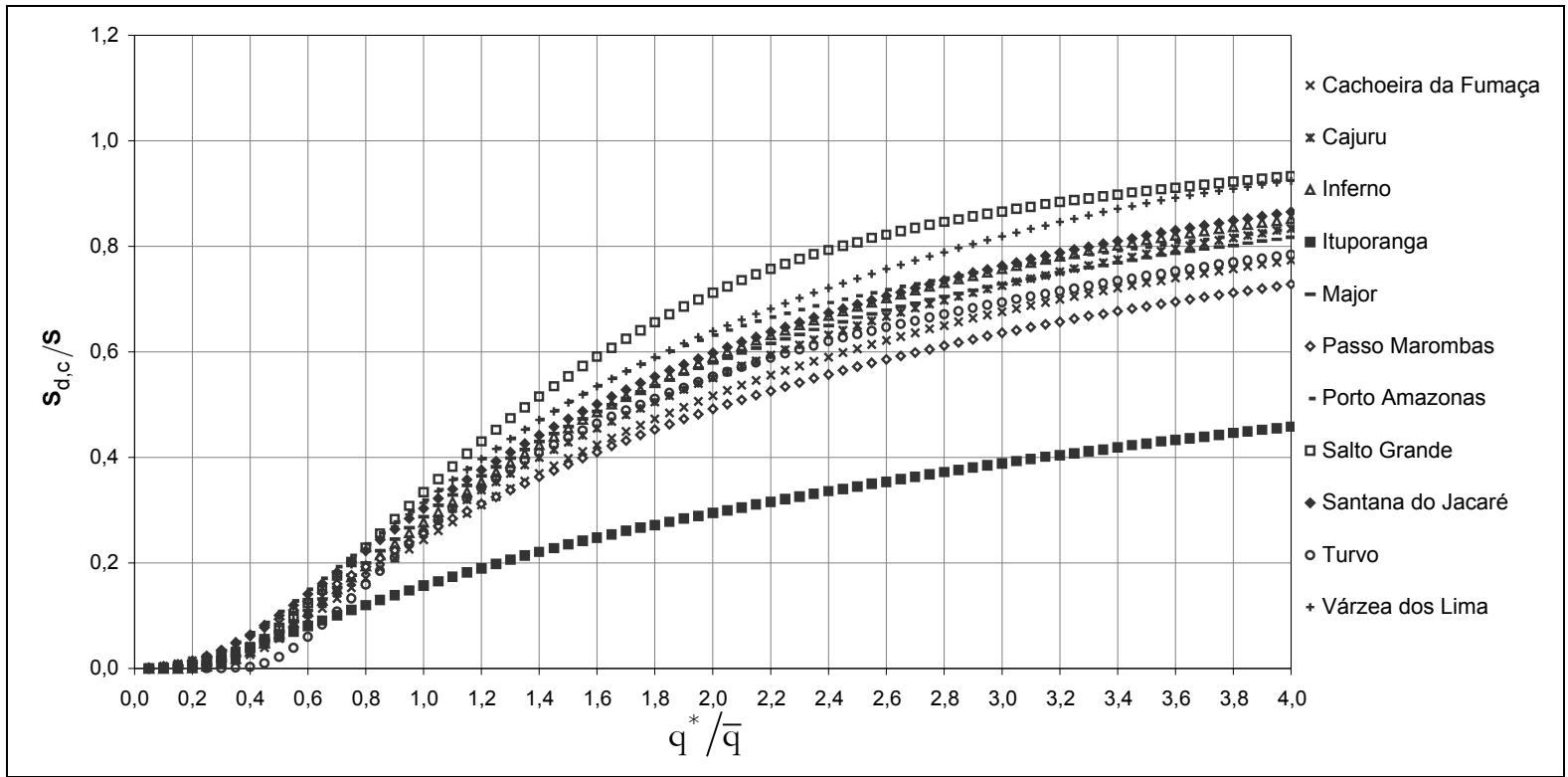

Figura 2 - Influência do nível de censura diário no desvio-padrão das vazões diárias.

entre a vazão média do período crítico e a vazão a $95 \%$ de permanência.

A figura 2 mostra a variação do desvio padrão das vazões médias diárias censuradas, em relação ao nível de censura para as $\mathrm{PCH}$ analisadas. Neste caso, ainda se nota um agrupamento razoável da maioria dos locais, com apenas um local (Itupo- ranga) mostrando um comportamento diferenciado.

Também aqui há uma tendência à redução do desvio-padrão das vazões censuradas para níveis de censura baixos, sendo essa tendência mais acentuada do que no caso das médias. Nota-se que mesmo para níveis de censura próximos ao dobro da 


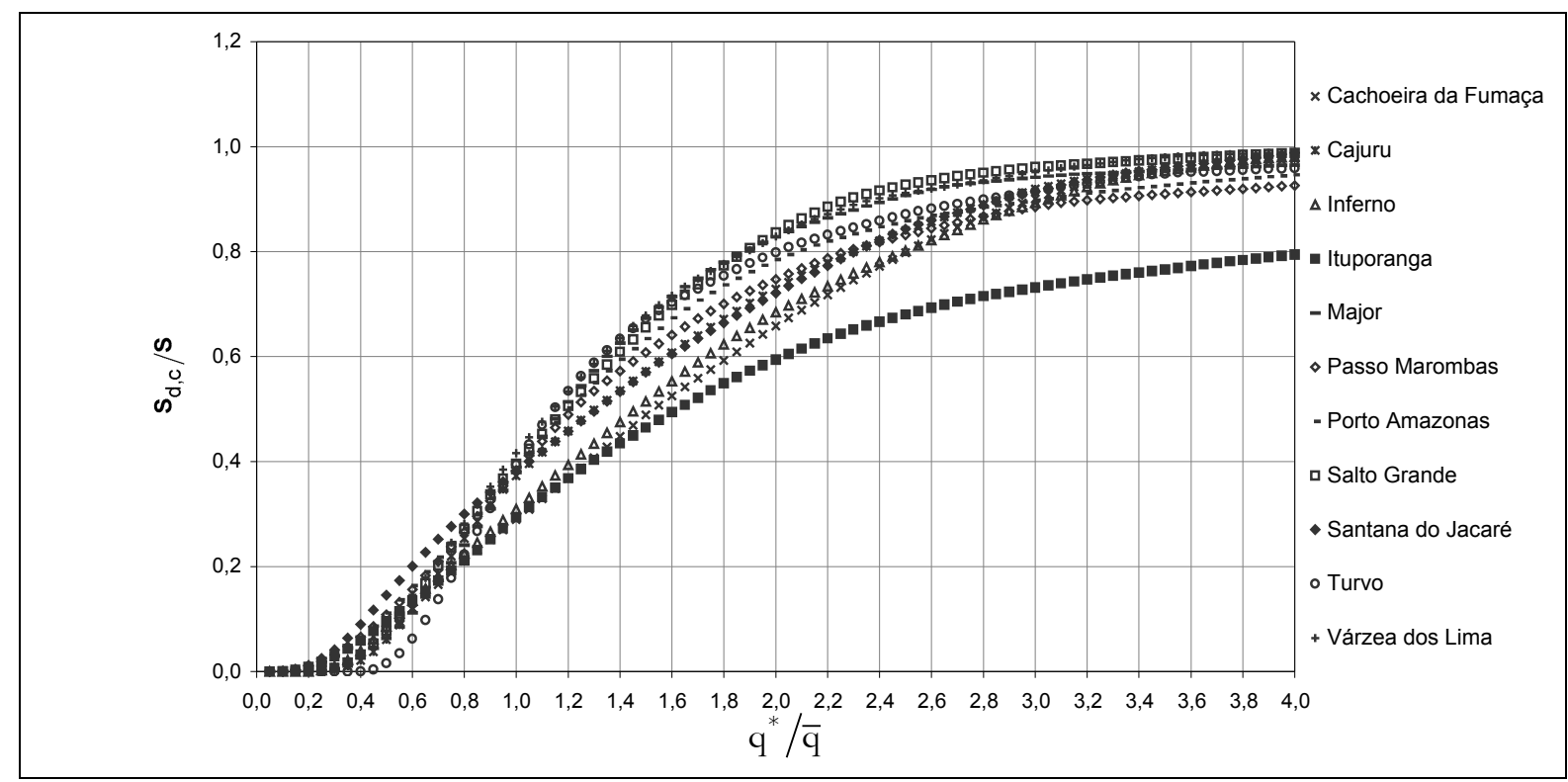

Figura 3 - Influência do nível de censura diário no desvio-padrão das vazões médias anuais.

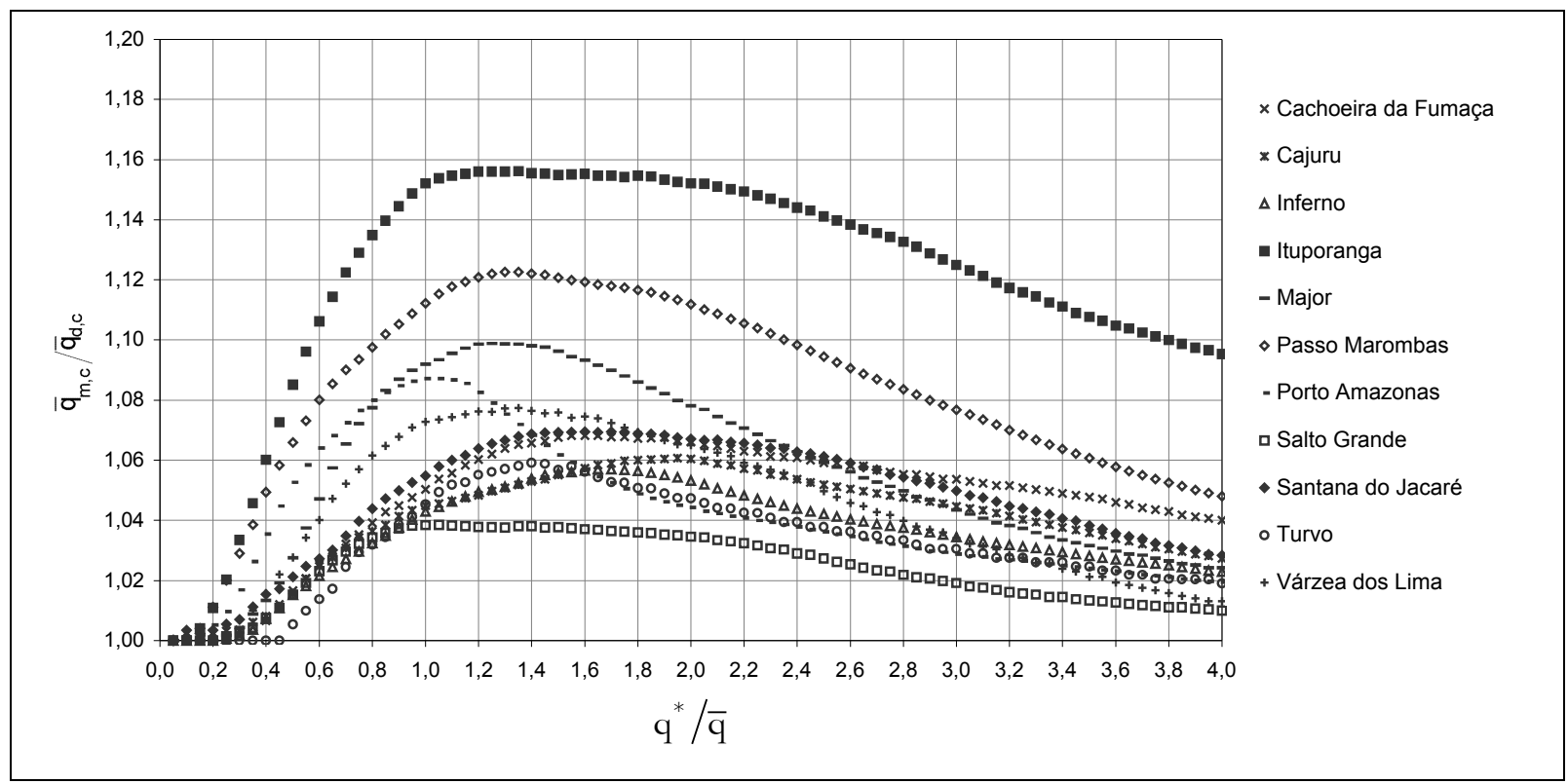

Figura 4 - Relação entre as vazões médias censuradas em função do nível de censura.

vazão média, a variabilidade das vazões turbináveis (censuradas) se reduz à cerca de $60 \%$ daquela das afluências naturais.

A figura 3 mostra a variação do desvio padrão das vazões médias anuais censuradas ao nível diário para as PCH analisadas. Nota-se ainda um comportamento muito similar entre os vários locais com uma diferenciação em Ituporanga. A redução do desvio-padrão em função do nível de censura é maior do que no caso das vazões diárias cerca de $75 \%$ para uma motorização correspondente ao dobro da vazão média.

A figura 4 ilustra a variação da relação entre as médias obtidas adotando uma censura em nível 


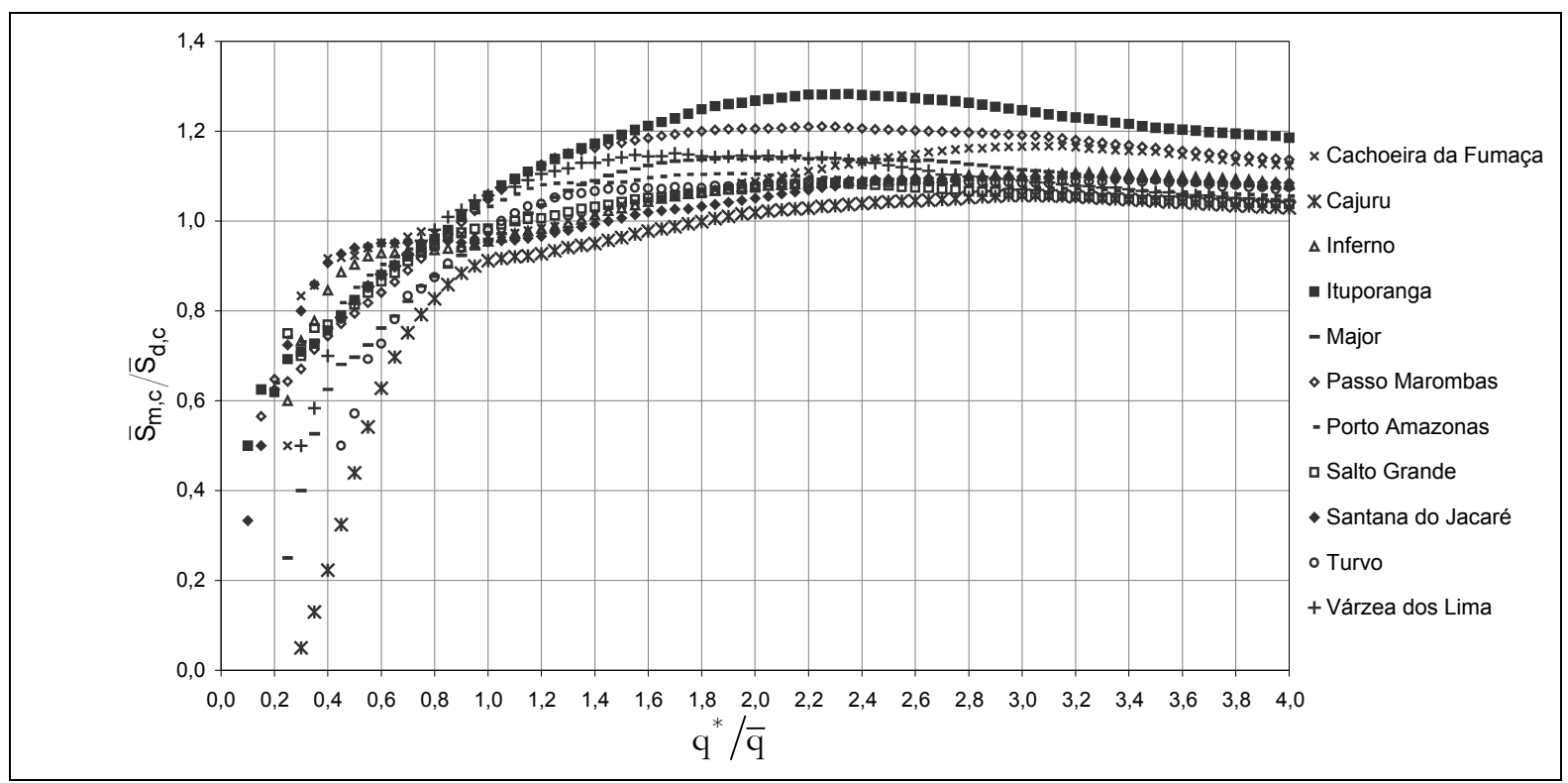

Figura 5 - Relação entre o desvio-padrão médio anual censurado no nível diário e mensal em função do nível de censura

de vazão média diária e de vazão média mensal para diversas PCH situadas nas regiões sul e sudeste do país. Nota-se que os efeitos diferenciados entre uma discretização mensal ou diária são maiores justamente na faixa correspondente a motorização das usinas analisadas, que pode ser considerada típica.

Observa-se que os efeitos da simplificação em usar, na análise energética de usinas $\mathrm{PCH}$, apenas séries de vazões médias mensais implica em superestimar as vazões médias censuradas e, por conseguinte, a energia assegurada.

A figura 4 mostra que a energia média determinada a partir de séries de vazões médias mensais, é de $4 \%$ a $16 \%$ superior àquela calculada com base em séries de vazões médias diárias. Isso significa que para a avaliação correta da energia assegurada, devese utilizar sempre a série de vazões médias diárias censuradas pelo engolimento máximo da usina. $\mathrm{O}$ uso de vazões médias mensais, como propõe a Resolução no 169 da ANEEL, de 03 de maio de 2001 (Aneel, 2001), pode levar a uma superestimação da energia média gerável de até $16 \%$ para os locais analisados.

A figura 5 ilustra a variação da relação entre o desvio-padrão das médias anuais censuradas no nível mensal e no nível diário.

Observa-se no caso do desvio-padrão das vazões médias anuais censuradas que a relação entre os valores obtidos com base na censura das médias mensais e das vazões diárias, em média, supera a unidade para níveis de censura superior à média de longo período. Para níveis de censura inferior à vazão média de longo período verifica-se uma tendência oposta.

Gomide (1986) demonstrou que a energia garantida de um sistema hidrelétrico pode ser estimada por:

$$
\mathrm{E}_{\mathrm{g}}=\overline{\mathrm{E}}-\mu \mathrm{S}
$$

sendo:

$\overline{\mathrm{E}}$ - energia média afluente turbinável;

S - desvio-padrão da energia afluente turbinável;

$\mu$ - energia equivalente $f\left(T_{r}, a\right)$;

$\mathrm{T}_{\mathrm{r}}$ - tempo de recorrência;

$\mathrm{a}-$ armazenamento plurianual equivalente.

O coeficiente $\mu$ depende da distribuição de probabilidades das afluências de energia, do risco assumido e do armazenamento plurianual equivalente, que é obtido descontando-se do armazenamento total aquele necessário à regularização sazonal e dividindo a diferença pelo desvio-padrão das afluências (Gomide e Cunha, 1981).

No caso particular de uma pequena usina a fio de água (PCH) adicionado a um sistema interligado, Fill (1989) mostrou que a energia garantida incremental pode ser determinada por: 


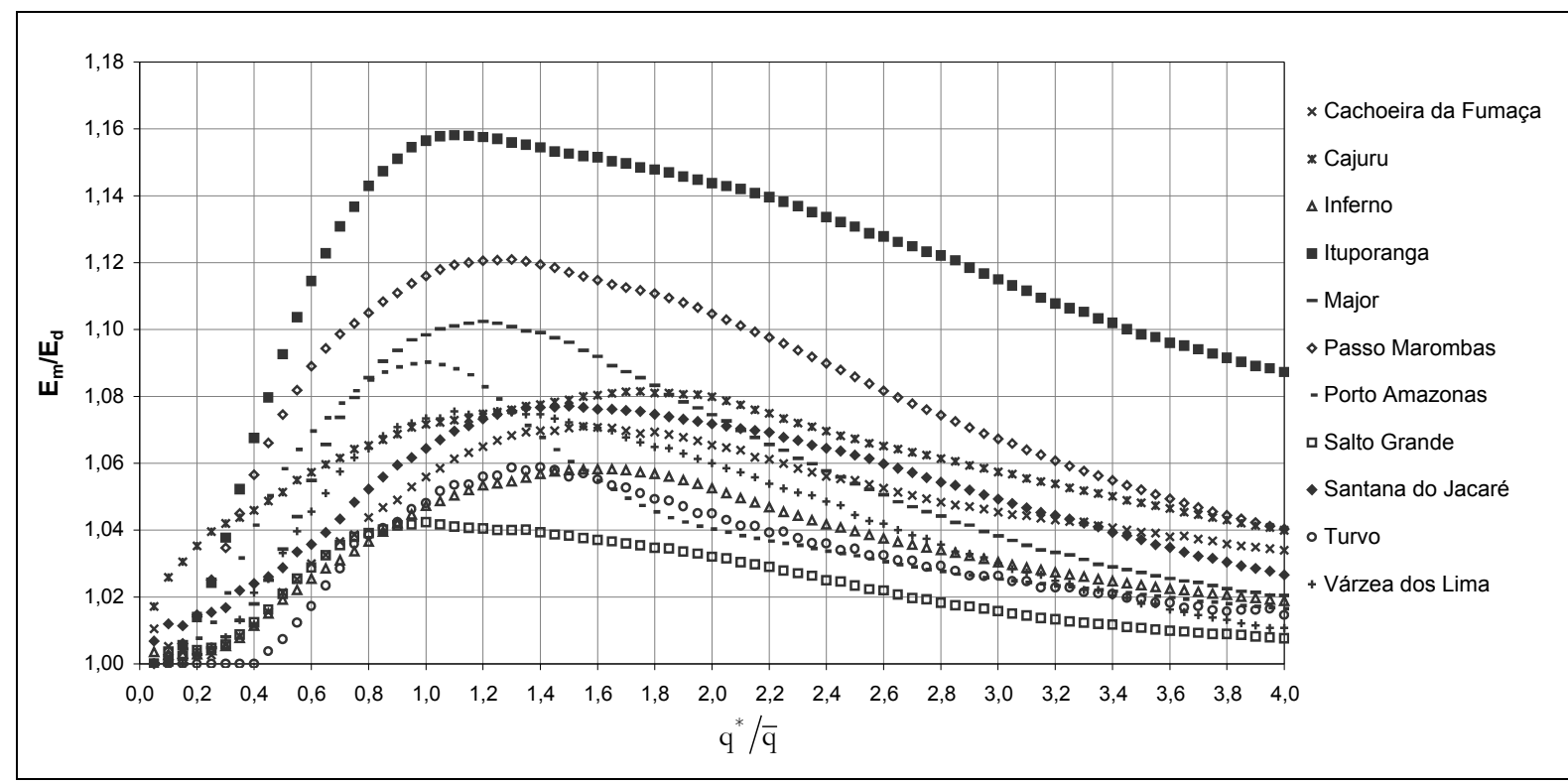

Figura 6 - Relação entre a energia garantida incremental censurada no nível mensal e diário em função do nível de censura.

$$
\Delta \mathrm{E}_{\mathrm{g}}=\mathrm{K}_{1} \overline{\mathrm{E}}-\mathrm{K}_{2} \rho \mathrm{S}
$$

Sendo $\overline{\mathrm{E}}$ a energia média afluente turbinável; S o desvio-padrão da energia afluente turbinável; $\rho$ o coeficiente de correlação entre as afluências a usina e ao sistema e $\mathrm{K}_{1} ; \mathrm{K}_{2}$ os coeficientes tabelados em função do risco e do armazenamento do sistema.

Nota-se que um erro positivo na avaliação da energia média e/ou um erro negativo na avaliação do desvio-padrão tende a conduzir a uma energia garantida superestimada. Entretanto, para o caso de erros positivos, tanto na média quanto no desviopadrão, como é o caso na maior parte da faixa de motorização das PCH's analisadas, não é possível prever de imediato o efeito na estimativa de energia garantida. Para avaliar esse efeito utilizou-se a equação (10) no cálculo da estimativa da energia garantida incremental para o caso de censura de vazões médias mensais e diárias e determinou-se a razão entre as respectivas estimativas da energia garantida para vários níveis de censura. Adotou-se para o sistema base, o sistema elétrico integrado Sul-Sudeste configuração 2001 que apresenta as características estatísticas (Kaviski, 2003):

Média: $33104 \mathrm{MW}$ med Desvio-padrão: .7053 MW med
Coeficiente de assimetria: 1,12

Coeficiente de autocorrelação:

Armazenamento plurianual:. $.14462 \mathrm{MW}$ ano

A média e o desvio-padrão das energias afluentes turbináveis da usina são calculados pelas equações (2) e (8).

Adotou-se nas análises uma confiabilidade correspondente à energia firme do sistema base equivalente a $80 \%$ num horizonte de 25 anos $\left(\mathrm{T}_{\mathrm{r}}=\right.$ 120 anos).

Os resultados são mostrados na figura 6 para as onze PCH analisadas. Observa-se que a energia garantida avaliada com base em séries de vazões médias mensais apresenta-se sistematicamente superior ao valor obtido quando a censura é realizada para as vazões diárias. Considerando-se que a censura nas vazões diárias é mais realista para simular o desempenho da usina segue-se que o uso direto de séries de vazões médias mensais para estimar a energia garantida de uma PCH leva a uma superestimativa entre $2 \%$ e $16 \%$, dependendo do local e do nível de censura.

O mesmo ocorre no caso de se atribuir a $\mathrm{PCH}$ uma energia assegurada igual à média das energias afluentes turbináveis como preconiza a ANEEL (Aneel, 2001) como pode ser visto na figura 4 que vale igualmente para energias, já que no caso de uma usina a fio de água a queda é constante e, portanto, a energia é um múltiplo da vazão. 


\section{CONGLUSÕES}

Percebe-se pela análise dos resultados do presente trabalho que, ao se estimar a energia garantida e em conseqüência a energia assegurada, é imprescindível que a análise considere as séries de vazões turbináveis médias diárias ou equivalentemente as suas propriedades estatísticas.

O uso de séries de vazões médias mensais tende a inflar as estimativas da energia gerável em uma PCH sem regularização a montante como é o caso da grande maioria deste tipo de usina. Os erros cometidos pelo uso das vazões médias mensais situam-se na faixa de $2 \%$ a $16 \%$ com um valor médio da ordem de 7,5\%. Como grande parte dos possíveis locais para construção de $\mathrm{PCH}$ não dispõe de estações hidrométricas no local ou próximo a este, muitas vezes é necessário recorrer a métodos de regionalização e/ou a geração de séries sintéticas de vazões diárias, para ser possível efetuar a censura ao nível diário.

Recomenda-se que no caso de pequenas usinas a fio de água incapazes de uma regularização que ultrapasse a escala diária, sejam revistos os métodos de avaliação energética baseados em séries de vazões médias mensais, pois conduzem sistematicamente a uma superavaliação das disponibilidades energéticas dessas usinas. Por outro lado, para tornar possível a utilização prática de séries diárias, é necessário que a ANEEL e outras entidades responsáveis pelo planejamento da expansão do sistema elétrico, invistam no desenvolvimento de métodos de regionalização para permitir a avaliação dos parâmetros estatísticos relevantes das vazões médias anuais censuradas ao nível diário.

O desenvolvimento de métodos regionais capazes de gerar séries sintéticas de vazões diárias em locais onde não há observações é altamente recomendável e deve ser contemplado por projetos de pesquisa específicos.

\section{AGRADECIMENTOS}

Os autores agradecem ao CNPq - Conselho Nacional de Desenvolvimento Científico e Tecnológico e ao CT-ENERG - Fundo Setorial de Energia pela concessão do apoio financeiro que possibilitou a realização do presente trabalho, inserido em um projeto de pesquisa denominado
"Comparação de Parâmetros Estatísticos de Séries de Vazões Censuradas ao Nível Mensal e Diário Aplicação para Pequenas Centrais Hidrelétricas". Ao Instituto de Tecnologia para o Desenvolvimento - LACTEC através do CEHPAR - Centro de Hidráulica e Hidrologia Prof. Parigot de Souza agradecem pelo fornecimento de dados que possibilitaram essa pesquisa.

\section{REFERÊNCIAS}

AGÊNCIA NACIONAL DE ENERGIA ELÉTRICA ANEEL. Resolução n. ${ }^{\circ}$ 394, de 4 de dezembro de 1998. Estabelece os critérios para 0 enquadramento de empreendimentos hidrelétricos na condição de pequenas centrais hidrelétricas. Diário Oficial da República Federativa do Brasil, Brasília, 7 dez. 1998-a.

AGÊNCIA NACIONAL DE ENERGIA ELÉTRICA ANEEL. Resolução n. ${ }^{\circ}$ 395, de 4 de dezembro de 1998. Estabelece os procedimentos gerais para registro e aprovação de estudos de viabilidade e projeto básico de empreendimentos de geração hidrelétrica, assim como da autorização para exploração de centrais hidrelétricas até $30 \mathrm{MW}$ e dá outras providências. Diário Oficial da República Federativa do Brasil, Brasília, 7 dez. 1998-b.

AGÊNCIA NACIONAL DE ENERGIA ELÉTRICA ANEEL. Resolução n. ${ }^{0} 169$, de 3 de maio de 2001. Estabelece critérios para a utilização do Mecanismo de Realocação de Energia - MRE, por centrais hidrelétricas não despachadas centralizadamente pelo Operador Nacional do Sistema Elétrico - ONS. Diário Oficial da República Federativa do Brasil, Brasília, 4 mai. 2001.

BADANHAN, L. F.; MARIOTONI, C. A. Potencial energético das pequenas centrais hidrelétricas analisado sob a óptica ambiental, levando-se em consideração a área ocupada pelos reservatórios. In: Congresso Latino-Americano: Geração e Transmissão de Energia Elétrica, 3., 1997, Campos do Jordão. Anais p. 259-264. Campos do Jordão: 1997.

BICCA, F. J. Estimativa de parâmetros estatísticos de vazões médias anuais censuradas em nível diário no contexto de pequenas centrais hidrelétricas. Curitiba, 2003. 126 p. Dissertação (Mestra- 
do) - Programa de Pós-Graduação em Engenharia de Recursos Hídricos e Ambiental, UFPR, 2003.

BRASIL. Resolução conjunta ANA/ANEEL $n$. (Sugestão a ser analisada na SOU). Minuta. 05/12/2002.

CANAMBRA ENGINEERING CONSULTANTS (1969). Power Study of South Brazil, App. 17, Curitiba, PR. 1969.

CLEMENTE, L.; RAMOS, F. Seleção da potência instalada de pequenas centrais hidrelétricas. In: Simpósio Brasileiro Sobre Pequenas e Médias Centrais Hidrelétricas, 3., 2002, Foz do Iguaçu. Anais, Foz do Iguaçu: 2002.

CLEMENTE, L.; RAMOS, F. Influência do MRE na energia assegurada das $\mathrm{PCH}$. In: Encontro LatinoAmericano e do Caribe em Pequenos Aproveitamentos Hidroenergéticos, 10., 2003, Poços de Caldas. Anais p. 44-51, Itajubá: 2003.

CGSE - Câmara de gestão da crise de energia elétrica. Propostas de metodologia de cálculo de energia assegurada de usinas hidrelétricas e para o mecanismo de realocação de energia - MRE - Energia Brasil - 07/06/2002.

ELETROBRÁS. Diretrizes para estudos e projetos de Pequenas Centrais Hidrelétricas. Disponível em:

<http://www.eletrobras.gov.br/atuacao/recursos/ diretrizes.asp> Acesso em: 10 dez. 2002.

FILL, H. D. Estudos Energéticos. Revista Paranaense de Desenvolvimento, Curitiba, n. 67, p.27-60, abr/mai/jun. 1979.

FILL, H. D. Avaliação analítica da energia garantida incremental de uma usina hidrelétrica. In: Simpósio Brasileiro de Recursos Hídricos, 8.,1989. Foz do Iguaçu. Anais, p.122-129, Foz do Iguaçu: 1989. v.1.

FILL, H. D.; CHELLA, M. R.; MINE, M. R. M.; KAVISKI, E.; FREITAS, C. Comparação de dois critérios para avaliação da energia assegurada de uma PCH. In: Encontro Latino-Americano e do Caribe em Pequenos Aproveitamentos Hidroenergéticos, 10., 2003, Poços de Caldas. Anais p.319324, Itajubá: 2003.

FORTUNATO, L. A. M.; ARARIPE, T. A.; ALBUQUERQUE, J. C. R.; PEREIRA, M. V. F. Conceitos básicos para o planejamento da expansão e operação. In: Introdução ao planejamento da expansão e operação de sistemas de produção de energia elétrica. Rio de Janeiro: Editora Universitária, 1990. Cap. 3.

GOMIDE, F. L. S. Teoria estocástica dos reservatórios aplicada ao planejamento de sistemas hidrelétricos. Curitiba: UFPR, 1986. (Tese de concurso para professor titular), 1986.

GOMIDE, F.L.S; CUNHA L.M. Dimensionamento de reservatórios para regularização de vazões. In: Simpósio Brasileiro de Hidrologia e Recursos Hídricos, 4., 1981, Fortaleza. Anais. São Paulo: 1981.

KAVISKI, E. Comunicação Pessoal, 2003.

NAGAYAMA, M.U. Parâmetros anuais de afluências censuradas na escala diária, utilizados no cálculo da energia garantida de pequenas hidrelétricas integradas. Curitiba, 1995. 85 p. Dissertação (Mestrado) - Programa de Pós-Graduação em Engenharia de Recursos Hídricos e Ambiental, UFPR, 1995.

Comparison of Statistical Parameters of a Series of Censored Flows to the Monthly and Daily LevelApplied to Small Hydro Plants

\section{ABSTRACT}

Fill (1989) proposed a formula to evaluate the incremental guaranteed energy provided by a small hydro plant (SHP) to an integrated electric power system. The formula input variables are the reliability of the system (return period), system storage and statistical parameters of the mean annual flows obtained from daily flows censored at the plant capacity. Nagayama (1995) and Bicca (2003) proposed a method to estimate these statistics at sites without observed stream flow data. Although most SHPs are run-of-river plants, unable to regulate flows at more than a daily scale, Brazilian regulatory agencies propose to use only mean monthly flows. This paper investigates the effect of censoring either daily or mean monthly flows on the estimates of the mean and standard deviation of mean annual flows as well as of the guaranteed energy, for eleven SHPs located in South and Southeast Brazil.

The study concludes that censoring only the mean monthly flows systematically overestimates the guaranteed energy of an SHP.

Key words: SHP, Energy, Water Resources 